https://doi.org/10.30910/turkjans.846472

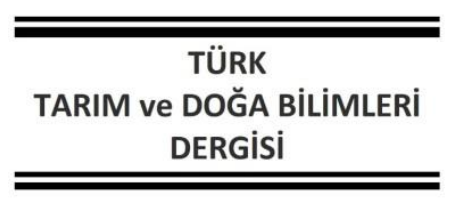

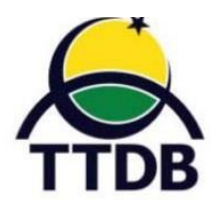

www.dergipark.gov.tr/turkjans

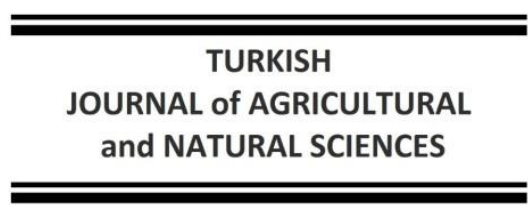

Araştırma Makalesi

\title{
Memeli Cinsiyet Hormonlarının in-vitro Şartlarda Bazı Hıyar (Cucumis sativus L.) Çeşitlerinin Rejenerasyonuna Etkisi
}

\author{
Hilal YILDIZ ${ }^{1}$, Ahmet EŞiTKEN² ${ }^{2}$ Özkan KAYA ${ }^{1 *}$ \\ ${ }^{1}$ Erzincan Bahçe Kültürleri Araştırma Enstitüsü, 24060 Erzincan \\ ${ }^{2}$ Selçuk Üniversitesi, Ziraat Fakültesi, Bahçe Bitkileri Bölümü, 42250 Konya \\ *Sorumlu Yazar: kayaozkan25@hotmal.com
}

Geliş Tarihi: 24.12.2020 Düzeltme Geliş Tarihi: 10.06.2021 Kabul Tarihi: 30.06.2021

\section{$\overline{\text { Öz }}$}

Memeli cinsiyet hormonları (progesteron, estron, testesteron, androsterone, $\beta$ estroidal ve 17 estradiol) hem bitkilerde hem de hayvanlarda doğal olarak meydana gelen steroidal bileşiklerdir. Bu hormonlar bitkilerin üreme fonksiyonları ve metabolizmaları için oldukça önemlidir. Bu çalışmada Hasankale ve Gordiyon hıyar çeşitlerinin kotiledon yaprakları kullanılarak kallus geliştirme ve rejenerasyon ortamında 2,4D, estron ve testesteronun farklı kombinasyonları uygulanarak in-vitro şartları altında embriyogenik kallus oluşumu, sürgün gelişimi ve kök oluşumu üzerine olan etkileri araştırılmıştır. Hasankale çeşidinde 10-5mM Estrone, 10-6m MEestrone, 10-7mM Estrone, 10-5mM Testesteron, 10-6mM Testesteron uygulamaları hariç diğer bütün uygulamalar \%100 kallus oluşuna neden olmuştur. Bununla beraber Gordiyon çeşidinde ise 2,4D, estrone ve testesteron kombinasyonlarının tamamında \%100 kallus oluşumu meydana gelmiştir. Rejenerasyon ortamına aktarılan Hasankale çeşidinde en yüksek embriyogenik kallus ve sürgün oluşumu \%93 ile 10-5mM Estrone, en yüksek kök oluşumu ise $\% 60$ ile $10-5 \mathrm{mM}$ Testesteron uygulamasında tespit edilmiştir. Gordiyon çeşidinde embriyogenik kallus oluşumu Hasankale çeşidine göre daha fazla olmuştur. Hem Estrone ve Testesteronun bireysel uygulamalarında hem de kombinasyonlarında \%100'lük gelişim gözlenmiştir. Gordiyon çeşidinde en yüksek sürgün oluşumu \%97 ile 10-7mM Estrone, en yüksek kök oluşumu ise \%90 ile 10-7mM Testesterone uygulamalarında tespit edilmiştir. Sonuç olarak hıyar türünde kotiledon yapraklara memeli cinsiyet hormon uygulanmalarının embriyogenik kallus, sürgün ve kök oluşumu üzerine önemli etkisinin olduğu gözlemlenmiştir.

Anahtar kelimeler: Hıyar, Cucumis sativus L., rejenerasyon, estrone, testesterone

\section{The Effect of Mammalian Sex Hormones on the Regeneration of Some (Cucumis sativus L.) Varieties in in-vitro Conditions}

\begin{abstract}
Mammalian sex hormones (progesterone, estrogen, testosterone, androsterone, $\beta$ estroidal and $17 \beta$ estradiol) are naturally occurring steroidal compounds in both plants and animals. These hormones are very important for the reproductive functions and metabolism of plants. In this study, the effects on embryogenic callus formation, shoot development and root formation under in-vitro conditions were investigated by applying different combinations of $2,4 \mathrm{D}$, estrone and testosterone in callus development and regeneration medium using cotyledon leaves of Hasankale and Gordion cucumber cultivars. All treatments in the Hasankale variety caused $100 \%$ callus except for $10^{-5} \mathrm{mM}$ Estrone, $10^{-6} \mathrm{mM}$ Eestrone, $10^{-7} \mathrm{mM}$ Estrone, $10^{-5} \mathrm{mM}$ Testosterone, $10^{-6} \mathrm{mM}$ Testosterone treatments. Additionally, in the Gordian variety, $100 \%$ callus formation occurred in all combinations of 2,4D, estrone and testosterone treatments. In the Hasankale variety transferred to the regeneration medium, the highest embryogenic callus and shoot formation (with 93\%) was detected in 10-5mM Estrone treatment, whereas the highest root formation (with 60\%) was detected in 10-5mM Testesteron treatment. Embryogenic callus formation was higher in Gordian variety compared to Hasankale variety. Plant improvement (100\%) was observed in individual application and combination of Estrone and
\end{abstract}


Testosterone. In the Gordian variety, the highest shoot formation was detected at $97 \%$ with $10^{-7} \mathrm{mM}$ Estrone and the highest root formation at $90 \%$ with $10^{-7} \mathrm{mM}$ Testesterone. To sum up, it has been observed that the application of mammalian sex hormones to cotyledon leaves in cucumber species contributes significantly to embryogenic callus, shoot and root formation.

Key words: Cucumber, Cucumis sativus L., regeneration, estrogen, testosterone

\section{Giriş}

Bitkilerde büyüme ve gelişme, bitkinin kendi içyapısı (metabolizması, genetik özellikleri, hormonları vb.) ve onu kuşatan dış ortam faktörlerinin (ışık, sıcaklık, su, toprak vb.) ortak etkileri sonucu meydana gelir (Kumlay ve Eryiğit, 2011). Bitkinin kendi genetik yapısı ve bünyesinde mevcut olan hormonlar, bitkilerdeki büyüme, gelişme ve diğer fizyolojik olayları yönlendiren, bir dokuda sentezlenerek büyüme ve gelişmenin gerçekleşeceği diğer dokulara taşınabilen, oluşturuldukları doku ve organlarda büyüme ve farklılaşmaya neden olan, çok düşük konsantrasyonlarda dahi etkisini gösterebilen endojen organik bileşiklerdir (Babaoğlu ve ark., 2001; Aydoğdu ve Boyraz, 2005; Kılıç, 2007). Bu bileşikler fitohormonlar veya bitki büyüme düzenleyicileri olarak da adlandırılırlar. Fitohormonların (oksin, sitokinin, giberellin gibi) invivo ve in-vitro ortamlarda dışarıdan uygulanmasıyla tohumda çimlenme, fide gelişiminde iyileşme, çiçek ve meyve oluşumunda artışlar sağlanabilmektedir (Güleryüz, 1982). Son yıllarda yapılan çalışmalarda bu fitohormonların yanı sıra farklı sinyal moleküllerinin de savunma ve sinyal iletiminde rol oynayan steroid gruplarının olduğu görülmüştür. Fitosteroller olarak ifade edilen bu maddelerin pek çok bitki türünde varlığına rastlanılmıştır (Milanesi ve Boland, 2004; Sarin, 2005). Steroidler, kimyasal haberci, kompleks gelişim ve üreme süreçlerinde membran bileşeni, sitotoksin, vitamin ve hormon olarak rol oynayan, düşük molekül ağırlıklı, lipofilik bileşiklerdir (Geuns, 1978; Sandor, 1979; Barrington, 1979). Ayrica onlar mineral ve protein metabolizmasına da katılırlar (İslam, 2014). Son zamanlarda sterol grupları arasında yer alan memeli cinsiyet hormonlarının (MCH); hem büyümeyi inhibe edici hem de büyümeyi teşvik edici etkileri gözlenmiştir (Erdal ve Dumlupinar, 2010). Bu hormonlar arasında yer alan $17 \beta-$ östradiol, androsteron, testosteron, östron ve progesteron gibi başlıca memeli cinsiyet hormonlarının oluşumu, bitkiler aleminde geniş bir alana yayılmıştır (Janeczko, 2012). Androsteron ve progesteronun araştırma yapılan bitkilerin \%80'inden fazla bir kısmında üretildiği gözlenirken, testesteronun aynı bitki türlerinin $\% 70$ 'inde ve östrojenlerin ise \%50'sinde üretildiği rapor edilmiştir (Speranza, 2010).

Son yıllarda yapılan çalışmalar sonucunda, memeli cinsiyet hormonlarının ve diğer hormonal maddelerin in-vitro biyoaktivitesi, kallus oluşumu, bitki fizyolojisinde çimlenme, embriyo gelişimi, ayrıca büyüme, gelişme ve çiçeklenme üzerine farklı konsantrasyonlarda uyarıcı rol oynadığı belirlenmiştir (Erdal ve Dumlupinar, 2010). Bitki gelişimi üzerine yapılan çalışmalarda östrojen ve testesteron uygulaması Melandrium dioecium, Rumex acetosa (kuzu kulağı) ve Anthoxanthum aristatum bitkilerindeki kök meristem aktivitesini artırdığı (Löve ve Löve, 1945), 0.1 $\mathrm{g} /$ bitki konsantrasyonda östron bezelye embriyosunun ve fidelerinin büyümesini uyardığı belirlenmiştir (Helmkamp ve Bonner, 1952). Ayçiçeği bitkisinde progesteron $(0.25 \mu \mathrm{g} / \mathrm{bitki})$ sürgün gelişimini artırırken kök gelişimini engellemiştir (Bhattacharya ve Gupta, 1981). Domates fidelerinde ise $1 \mu \mathrm{M}$ konsantrasyonda estron ve $17 \beta$-estrodiol muamelesinin kök büyümesini engellediği görülmüştür (Janeczko ve Skoczowski, 2005). Ayrıca $1 \mu \mathrm{M}$ konsantrasyonunda uygulanan östrojen ve progesteron kışlık buğdayda in-vitro da yaprak ve kök gelişimini uyarmıştır. Fakat aynı steroidlerin bu seviyesinden 10 kat yüksek konsantrasyonunun büyümeyi engellediği de rapor edilmiştir (Janeczko, 2000). Ancak memeli cinsiyet hormonlarının doku kültüründeki etkileriyle ilgili çalışmalar oldukça sınırlıdır ve hatta yok denecek kadar azdır. Yapılan bir çalışmada $17 \beta$-estrodiolün doku kültüründe Daucus carota kallusunun gelişimini \%100 artırdığı ve klorofil sentezini uyardığı belirlenmiştir. Aynı hormon Polygonatum verticillatum (mührü süleyman)'da kallus gelişimini artırmıştır (Janeczko, 2001). Androsteron ve androstenoidler kışlık buğday bitkisinin hem çimlenmesini, hem de skutellumda kallus dokusunun çoğalmasını artırmıştır (Janeczko, 2000). Östrojenler, özellikle östron olgun olmayan embriyoların çimlenmesini sınırlamış, fakat kallus gelişimini etkilememişlerdir. Tüm bu olumlu gelişmelerden yola çıkarak mevcut çalışma ile; memeli cinsiyet hormonları ve onların farklı oranlardaki konsantrasyonlarının hıyar yapraklarına uygulanarak in-vitro şartlar altında embriyogenik 
kallus oluşumu, sürgün ve rejenerzasyonu gelişimi üzerine olan etkileri belirlenmeye çalışılmıştır.

\section{Materyal ve Metot}

Memeli cinsiyet hormonlarının hıyar bitkisinde embriyogenik kallus oluşumu, sürgün gelişimi ve kök oluşumuna etkilerinin gözlenmesi amacıyla yapılan bu çalışmada; eksplant olarak musluk suyunda yıkanarak \%70'lik etil alkolde (EtOH) 3dk karıştırılarak steril kabin içerisinde 3 defa steril saf suyla yıkanmış ve birkaç damla Tween 20 (Sigma) içeren \%10'luk sodyum hipokloritte 15 dakika karıştırılmak suretiyle yüzey sterilizasyonu yapılmış hıyar tohumları kullanılmıştır.
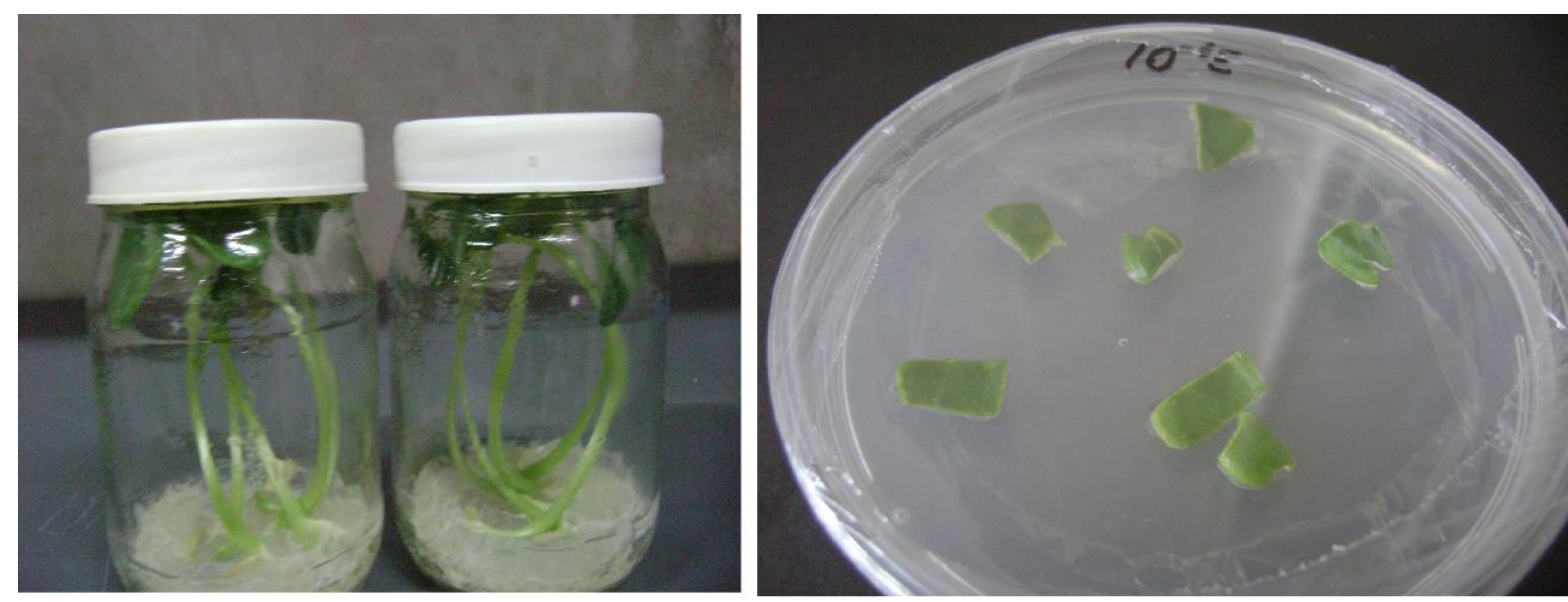

Şekil 1. Hasankale ve Gordiyon çeşitlerinde tohum çimlendirme ve kallus oluşturma ortamları
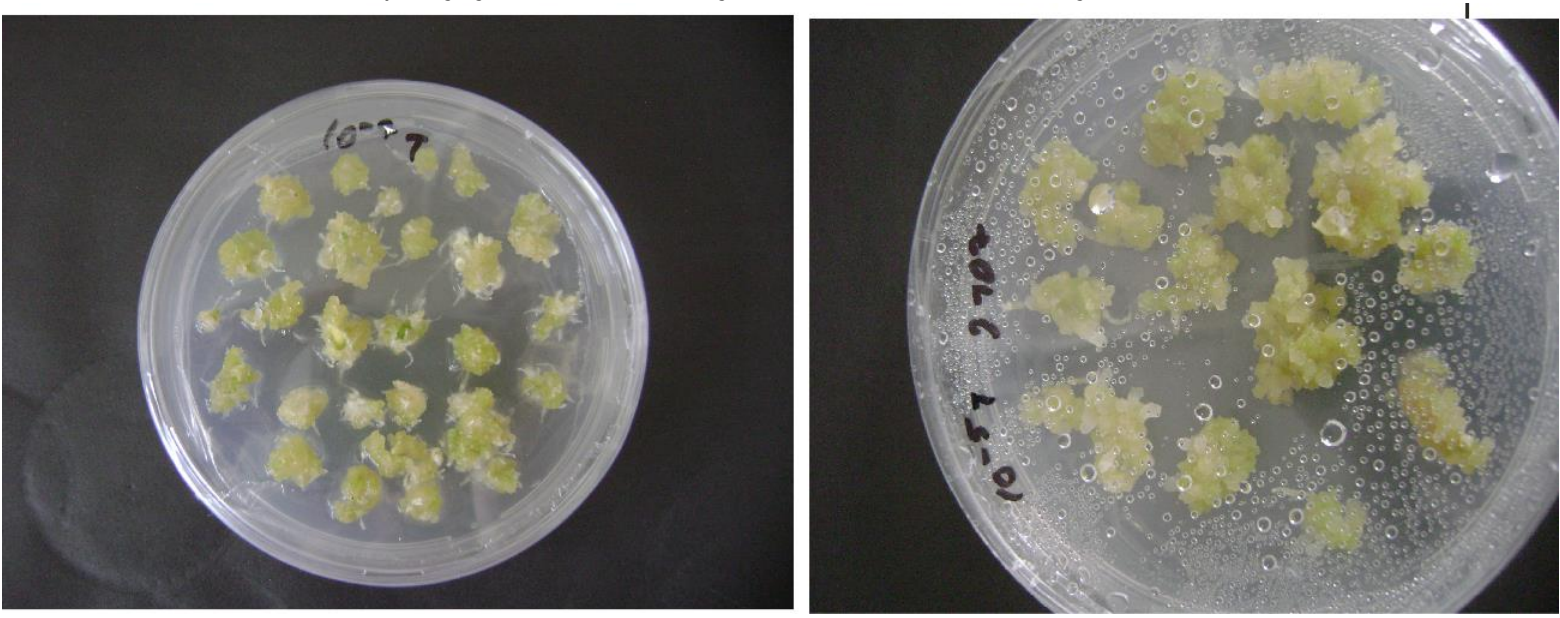

Şekil 2. Hasankale ve Gordiyon çeşitlerinde kallus oluşumları
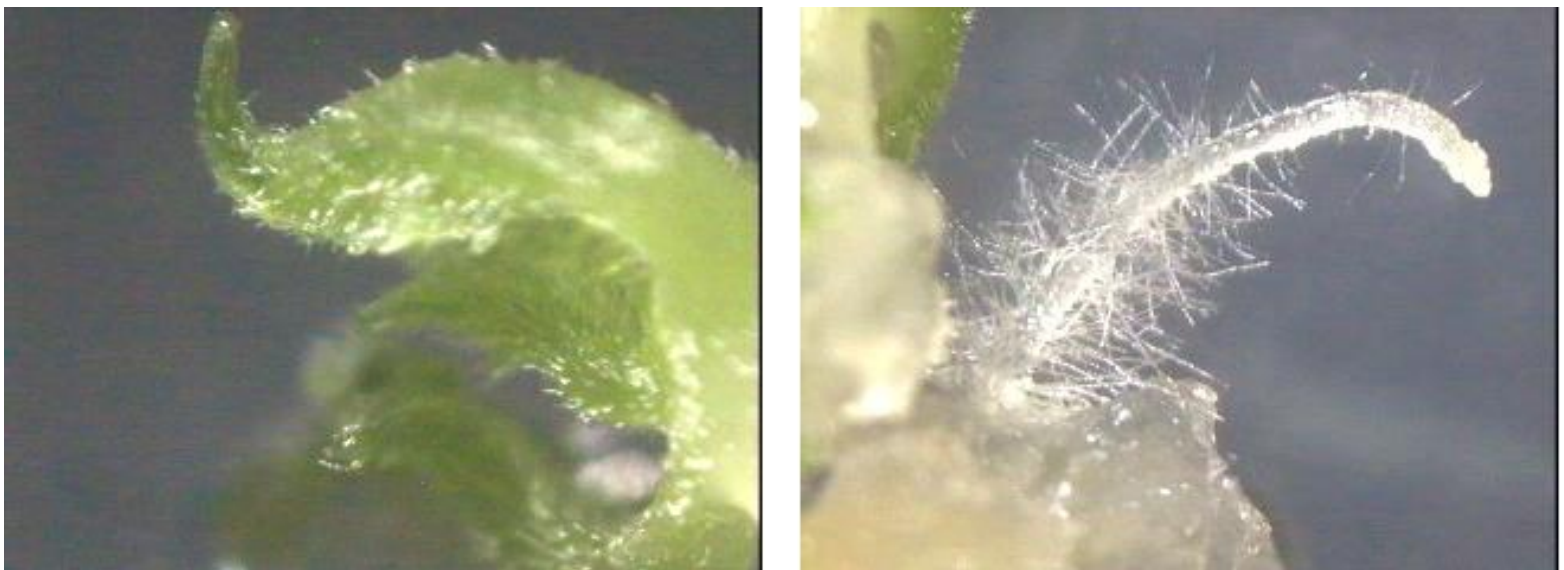

Şekil 3. Hasankale ve Gordiyon çeşitlerinde rejenerasyon 
Tohumlar in-vitro şartlarda hormonsuz MS ortamında kavanozlarda çimlendirilerek (Şekil 1) elde edilen fidelerin kotiledon yapraklarından alınmıştır. Hasankale ve Gordiyon hıyar çeşitlerinin kotiledon yaprakları 2,4D'nin 3 dozu (1, 2, 3mg/l), estron ve testesteronun 3 dozu (10-5mM, 10-6mM, $10-7 \mathrm{mM})$ ve bunların farklı kombinasyonlarının (10-5E+1 2,4 D, 10-5E+2 2,4 D, 10-5E+3 2,4 D, 10$6 \mathrm{E}+12,4 \mathrm{D}, 10-6 \mathrm{E}+2$ 2,4 D, 10-6E+3 2,4 D, 10-7E+1 2,4 D, 10-7E+2 2,4 D, 10-7E+3 2,4 D, 10-5T+1 2,4 D, 10-5T+2 2,4 D, 10-5T+3 2,4 D, 10-6T+1 2,4 D, 10$6 \mathrm{~T}+2$ 2,4 D, 10-6T+3 2,4 D, 10-7T+1 2,4 D, 10-7T+2 2,4 D, 10-7T+3 2,4 D) kullanıldığı kallus geliştirme ortamına alınmıştır (Şekil 2). Gelişmiş kalluslar steril kabinde TDZ'nin 3 dozu (1,2,3 mg/l), estron ve testesteronun 3 dozu (10-5 mM, 10-6 mM, 10-7 $\mathrm{mM}$ ) ve bunların farklı kombinasyonlarının (1 TDZ, 2 TDZ, 3 TDZ, 10-5E, 10-6E, 10-7E, 10-5T, 10-6T, 107T, 10-5E+1 TDZ, 10-5E+2 TDZ, 10-5E+3 TDZ, 106E+1 TDZ, 10-6E+2 TDZ, 10-6E+3 TDZ, 10-7E+1 TDZ, 10-7E+2 TDZ, 10-7E+3 TDZ, 10-5T+1 TDZ, 10-5T+2 TDZ, 10-5T+3 TDZ, 10-6T+1 TDZ, 10-6T+2 TDZ, 106T+3 TDZ, 10-7T+1 TDZ, 10-7T+2 TDZ, 10-7T+3 TDZ) olduğu ikinci ortam olan rejenerasyon ortamına aktarılmıştır (Şekil 3). Kültüre alınan uygulamalar 6 haftalık süre içinde sürgün gelişimi ve kök oluşumu bakımından incelenmiştir.

Çalışmada sonuçların değerlendirilmesi için JUMP 7.0.1 (version. 7.0, SAS Institute Inc., Cary, NC) istatistik programından yararlanılmıştır. Araştırma tam şansa bağlı faktöriyel deneme desenine göre planlanmış ve analizler 4 tekerrürlü olarak yürütülmüştür. Ayrıca her bir petri kabı tek bir tekerrür olarak ele alınmıştır. Veriler tam şansa bağlı deneme planına göre Genel Linear modelde varyans analizini (ANOVA) ile değerlendirilmiştir. Elde edilen verilere ait ortalamalar arasındaki farklar \%1 önem seviyesinde Duncan çoklu karşılaştırma testine tabi tutulmuştur.

\section{Bulgular ve Tartışma}

Bu çalışmada öncelikle in-vitro şartlar altında hormonsuz MS ortamında Gordiyon ve Hasankale hıyar çeşitlerinin tohumları çimlendirilmiş (Şekil 1) ve ardından çimlendirme sonucu çıkan kotiledon yapraklar farklı hormonların (Östrojen, Testesteron, 2,4D) tek ve kombinasyonlarının kullanıldığı MS ortamına aktarılmıştır (Şekil 1). İlk ortamda kök ve kallus oluşumları araştırılmış, sonuç olarak uygulamaların sürgün gelişimi ile kök oluşumları üzerine etkileri istatistiksel $(p<0.01)$ olarak önemli bulunmuştur (Çizelge 1). En fazla kök gelişimi \%100 ile 10-5 T+2 2,4 $D$ ve 10-5 T+3 2,4 D uygulamalarında gözlenmiştir. Kontrol, estrone ve testesteronun bireysel dozları ile 10-6E, 10-6T ve 10-7T uygulamalarında kök oluşumu meydana gelmemiştir. Kallus oluşumunun $\% 100$ orana uluştığı uygulamalar sırasıyla 2 2,4 D, 3 2,4 D, 10-5 $E+1$ 2,4 D, 10-5 E+3 2,4 D, 10-7 E+1 2,4D, 10-7E+2 2,4D, 10-7E+3 2,4D, 10-5T+2 2,4D, 10-5T+3 2,4D, 10-6T+3 2,4D, 10-7T+1 2,4D, 10-5 T+3 2,4D dozlarında belirlenmiştir. Kontrol, estrone ve testesteron uygulamalarının bireysel dozlarında kallus oluşumu gözlenmemiştir. Öte yandan kallus ve kök oluşumu çeşitlere göre önemli ölçüde farklılık göstermiştir (Çizelge 2). Kök oluşumu Gordiyon çeşidinde (\%28.73), kallus oluşumu ise Hasankale (\%78.57) çeşidinde daha yüksek bulunmuştur. Memeli cinsiyet hormonları yapısal olarak steroidal bileşikler olup bitkilerin gelişimi ve büyümesinin temel süreçlerini kontrol etmede önemli rol oynadığı rapor edilmiştir (Speranza, 2010). Bununla beraber dışardan uygulanan steroid hormonlarının, hücre bölünmesini, kök ve sürgün büyümesini, embriyo gelişimini, polen çimlenmesini, bitkinin çiçeklenmesini ve gelişmesini tetiklediğine dair bilgiler bulunmaktadır (Speranza, 2010; Janeczko ve ark., 2012). Nitekim in-vitro metotlar kullanılarak bitkilerdeki steroid etkinliğinin gösterimi, memeli cinsiyet hormonlarının veya onların öncü maddelerinin invitro şartlarda bitki gelişimini modifiye etmek için kullanılmasına öncülük ettiği belgelenmiştir (Janeczko ve ark., 2003). Ayrıca çalışmamızda hıyarın kotiledon yapraklarından rejenerasyon yoluyla bitki elde edilmesi, kullanılan farklı çeşitlerin ve konsantrasyonlardaki memeli cinsiyet hormonlarının gösterdikleri performanslarının karşılaştırılması sonucunda kallus oluşum ortamında cinsiyet hormonlarının önemli bir etkisinin olduğu belirlenmiştir. Bulgularımızda kallus oluşumu testesterone ve estronenun 2,4D ile farklı kombinasyonlarında yüksek oranlarda tespit edilmiş olup sonuçlar yapılan çalışmalarla paralellik göstermiştir. Nitekim $17 \beta$ estrodiol doku kültüründe Daucus carota kallusunun büyümesini \%100'e kadar artırdığı ve klorofil sentezini uyardığı rapor edilmiştir. Aynı hormon uygulamaları Polygonatum verticillatum kallusunun çoğalmasını ve indüksiyonunu artırmıştır (Janeczko ve Skoczowski, 2005). Androsteron ve androstenoidler kışlık buğday bitkisinin hem çimlenmesini, hem skutellumda kallus dokusunun çoğalmasını ve indüksiyonunu artırmıştır (Janeczko, 2000). Östrojenler ise (özellikle östron) olgunlaşmamış embriyonun büyümesini sınırlandırmış, fakat kallusun indüksiyonunu etkilememiştir. Çalışmamızın ilk ortamında çeşitler arası kök ve kallus oluşumları karşılaştırılmış ve en iyi kök oluşumu Gordiyon çeşidinde, en iyi kallus oluşumu ise Hasankale çeşidinde tespit edilmiştir. 
Illk ortamda oluşan kök ve kallus yapıları estrone, testesteron ve TDZ'nin tek ve kombinasyon halinde kullanıldıkları rejenerasyon ortamına aktarılmıştır. Her iki çeşitte de embriyogenik kallus, sürgün ve kök oluşumları istatistiki açıdan önemli bulunmuştur (Çizelge 3). Gordiyon çeşidinde embriyogenik en yüksek kallus oluşumu \%100 oranında 1 TDZ, 2 TDZ, 10-5E, 10-6 E, 10-7 E, 10-5 T, 10-6 T, 10-5 T+1 TDZ, 10-5 T+2 TDZ, 10-5 T+3 TDZ, 10-6 T+1 TDZ uygulamalarında gözlenmiştir. Sürgün oluşumunda en yüksek oran
\%96,67 ile 10-7E uygulamasında olurken, en düşük oran \%7,33 ile 10-6T+2 TDZ uygulamasında saptanmıştır. Kök oluşumunda en yüksek değerler \%86 ile kontrol, \% 90 ile 10-7 T, \%85 ile 10-6 T uygulamalarında olmuş, diğer uygulamaların bazılarında birbirine oldukça yakın oranlarda köklenme görülmüş ve bazılarında ise hiç köklenme olmamıştır. Kök oluşumu genel iti bari ile estrone ve testesteronun tek başına oldukları uygulamalarında gözlenmiştir.

Çizelge 1. Uygulamaların kök ve kallus oluşumuna etkisi

\begin{tabular}{|c|c|c|}
\hline Uygulamalar & Kök & Kallus \\
\hline Kontrol & - & - \\
\hline $12,4 \mathrm{D}$ & $40.50 \mathrm{bc}$ & $83.17 b$ \\
\hline $22,4 \mathrm{D}$ & $33.17 \mathrm{c}$ & 100 a \\
\hline $32,4 \mathrm{D}$ & $50.00 \mathrm{bc}$ & $100 \mathrm{a}$ \\
\hline $10^{-5} \mathrm{E}$ & - & - \\
\hline $10^{-6} \mathrm{E}$ & - & - \\
\hline $10^{-7} \mathrm{E}$ & - & - \\
\hline $10^{-5} \mathrm{~T}$ & - & - \\
\hline $10^{-6} \mathrm{~T}$ & - & - \\
\hline $10^{-7} \mathrm{~T}$ & $50.00 \mathrm{bc}$ & $50 \mathrm{c}$ \\
\hline $10^{-5} E+12,4 D$ & $33.30 \mathrm{c}$ & $100 \mathrm{a}$ \\
\hline $10^{-5} \mathrm{E}+22,4 \mathrm{D}$ & $45.17 b c$ & $97.67 \mathrm{a}$ \\
\hline $10^{-5} \mathrm{E}+32,4 \mathrm{D}$ & - & $100 \mathrm{a}$ \\
\hline $10^{-6} \mathrm{E}+12,4 \mathrm{D}$ & - & $50 \mathrm{c}$ \\
\hline $10^{-6} \mathrm{E}+22,4 \mathrm{D}$ & - & $50 \mathrm{c}$ \\
\hline $10^{-6} \mathrm{E}+32,4 \mathrm{D}$ & - & $50 \mathrm{c}$ \\
\hline $10^{-7} E+12,4 D$ & $50.00 \mathrm{bc}$ & $100 \mathrm{a}$ \\
\hline $10^{-7} E+22,4 D$ & $33.30 \mathrm{c}$ & $100 a$ \\
\hline $10^{-7} E+32,4 D$ & $59.50 \mathrm{~b}$ & $100 \mathrm{a}$ \\
\hline $10^{-5} \mathrm{~T}+12,4 \mathrm{D}$ & $50.00 \mathrm{bc}$ & $50 \mathrm{c}$ \\
\hline $10^{-5} \mathrm{~T}+22,4 \mathrm{D}$ & $100 a$ & $100 \mathrm{a}$ \\
\hline $10^{-5} \mathrm{~T}+32,4 \mathrm{D}$ & $100 \mathrm{a}$ & $100 \mathrm{a}$ \\
\hline $10^{-6} \mathrm{~T}+12,4 \mathrm{D}$ & - & $50 \mathrm{c}$ \\
\hline $10^{-5} \mathrm{~T}+22,4 \mathrm{D}$ & $100 a$ & $100 \mathrm{a}$ \\
\hline $10^{-5} \mathrm{~T}+32,4 \mathrm{D}$ & $100 \mathrm{a}$ & $100 \mathrm{a}$ \\
\hline $10^{-6} \mathrm{~T}+12,4 \mathrm{D}$ & - & $50 \mathrm{c}$ \\
\hline $10^{-6} \mathrm{~T}+22,4 \mathrm{D}$ & - & $50 \mathrm{c}$ \\
\hline $10^{-6} \mathrm{~T}+32,4 \mathrm{D}$ & - & $100 \mathrm{a}$ \\
\hline $10^{-7} \mathrm{~T}+12,4 \mathrm{D}$ & - & $100 \mathrm{a}$ \\
\hline $10^{-7} \mathrm{~T}+22,4 \mathrm{D}$ & - & $50 \mathrm{c}$ \\
\hline $10^{-7} \mathrm{~T}+32,4 \mathrm{D}$ & - & $100 \mathrm{a}$ \\
\hline LSD0.01 & $17.09 *$ & $2.31^{*}$ \\
\hline
\end{tabular}

* Değerler açı transformasyonu yapılmış değerlere aittir.

Çizelge 2. Uygulamarın çeşitlerde kök ve kallus oluşumuna etkisi

\begin{tabular}{lll} 
Çeşitler & Kök & Kallus \\
\hline Hasankale & $17.36 \mathrm{~b}$ & $78.57 \mathrm{a}$ \\
Gordion & $28.73 \mathrm{a}$ & $48.63 \mathrm{~b}$ \\
LSD0.01 & $4.57^{*}$ & $0.62^{*}$ \\
\hline
\end{tabular}

\footnotetext{
* Değerler açı transformasyonu yapılmış değerlere aittir.
} 
Çizelge 3. Uygulamaların 2 ayrı çeşitteki sürgün ve kök oluşumuna etkileri

\begin{tabular}{cccc}
\hline Çeşitler & Embriyogenik kallus & Sürgün & Kök \\
\hline Hasankale & $26.73 \mathrm{~b}$ & $13.24 \mathrm{~b}$ & 14.69 \\
Gordion & $83.75 \mathrm{a}$ & $40.69 \mathrm{a}$ & 17.48 \\
LSD0.01 & $8.90^{*}$ & $8.58^{*}$ & $0 ̈ D$ \\
\hline
\end{tabular}

* Değerler açı transformasyonu yapılmış değerlere aittir.

Hasankale çeşidinde en yüksek embriyogenik kallus oluşumu \%93,33 ile 10-5E uygulamasında gözlenirken, 1 TDZ, 2 TDZ, 10-6 T, 10-7 T, 10-5 E+3 TDZ, 10-5 T+2 TDZ, 10-7 T+1 TDZ uygulamalarında hiç embriyogenik kallus oluşumu saptanmamıştır. Sürgün oluşumu ise $\% 93,33$ ile $10-5 \mathrm{E}$ uygulamasında en yüksek değeri vermiştir. Kök oluşumu en yüksek \%59,67 ile 10-5 T olurken diğer uygulamalarda bazılarında çok az köklenme gözlenmiş bazılarında ise hiç köklenme olmamıştır. $\mathrm{Bu}$ durumda embriyogenik kallus ve sürgün oluşumunda en iyi etki estrone uygulamalarında gözlenmiştir.

Çizelge 4. Uygulamaların çeşitlerdeki sürgün ve kök oluşumlarına etkileri

\begin{tabular}{|c|c|c|c|c|c|c|}
\hline \multirow[b]{2}{*}{ Uygulamalar } & \multicolumn{3}{|c|}{ Gordiyon } & \multicolumn{3}{|c|}{ Hasankale } \\
\hline & $\begin{array}{c}\text { Embriyogenik } \\
\text { kallus }\end{array}$ & Sürgün & Kök & $\begin{array}{l}\text { Embriyogenik } \\
\text { kallus }\end{array}$ & Sürgün & Kök \\
\hline Kontrol & $62.33 \mathrm{ab}$ & 48 abcd & $86 a$ & $22.33 \mathrm{~cd}$ & $13 \mathrm{~cd}$ & $53.67 a b$ \\
\hline $1 \mathrm{TDZ}$ & 100 a & $43.67 \mathrm{abcd}$ & $6.67 b$ & - & - & $33.33 a b$ \\
\hline $2 \mathrm{TDZ}$ & $100 \mathrm{a}$ & 31 bcd & - & - & - & - \\
\hline 3 TDZ & $53 \mathrm{~b}$ & $10.33 \mathrm{~cd}$ & - & $26 \mathrm{~cd}$ & $11 \mathrm{~cd}$ & $33.33 \mathrm{ab}$ \\
\hline $10^{-5} \mathrm{E}$ & $100 \mathrm{a}$ & 61 abcd & $32.67 b$ & 93.33 a & 93.33 a & $41.33 \mathrm{ab}$ \\
\hline $10^{-6} \mathrm{E}$ & $100 \mathrm{a}$ & $38.33 \mathrm{abcd}$ & 3.33 b & $33.33 \mathrm{bcd}$ & $33.33 \mathrm{bcd}$ & $16 \mathrm{ab}$ \\
\hline $10^{-7} \mathrm{E}$ & $100 \mathrm{a}$ & 96.67 a & $73.33 \mathrm{a}$ & $66.67 \mathrm{abc}$ & $66.67 \mathrm{ab}$ & $6.33 a b$ \\
\hline $10^{-5} \mathrm{~T}$ & $100 \mathrm{a}$ & 31 bcd & $28.33 b$ & $44.67 \mathrm{abcd}$ & $10 \mathrm{~cd}$ & $59.67 \mathrm{a}$ \\
\hline $10^{-6} \mathrm{~T}$ & $100 \mathrm{a}$ & $75 a b$ & 85 a & - & - & - \\
\hline $10^{-7} \mathrm{~T}$ & $62 a b$ & $29.67 \mathrm{bcd}$ & $90.33 \mathrm{a}$ & - & - & $46 a b$ \\
\hline $10^{-5} \mathrm{E}+1 \mathrm{TDZ}$ & $54.33 \mathrm{~b}$ & $21.67 \mathrm{bcd}$ & - & $29 \mathrm{~cd}$ & - & $9.67 \mathrm{ab}$ \\
\hline $10^{-5} \mathrm{E}+2 \mathrm{TDZ}$ & $9433 a b$ & $36.33 \mathrm{bcd}$ & - & $16 \mathrm{~cd}$ & - & - \\
\hline $10^{-5} \mathrm{E}+3 \mathrm{TDZ}$ & $93.33 \mathrm{ab}$ & $46.67 \mathrm{abcd}$ & $10 b$ & - & - & - \\
\hline $10^{-6} \mathrm{E}+1 \mathrm{TDZ}$ & $83.33 a b$ & $60.67 \mathrm{abcd}$ & - & 45 abcd & - & - \\
\hline $10^{-6} \mathrm{E}+2 \mathrm{TDZ}$ & $54.33 \mathrm{~b}$ & 45 abcd & - & 30.33 bcd & - & - \\
\hline $10^{-6} \mathrm{E}+3 \mathrm{TDZ}$ & $82 a b$ & 36 bcd & - & $38.67 \mathrm{abcd}$ & - & - \\
\hline $10^{-7} \mathrm{E}+1 \mathrm{TDZ}$ & $93.33 \mathrm{ab}$ & $67.67 \mathrm{abc}$ & - & $24.33 \mathrm{~cd}$ & $4.67 \mathrm{~cd}$ & - \\
\hline $10^{-7} \mathrm{E}+2 \mathrm{TDZ}$ & $86.67 \mathrm{ab}$ & 58 abcd & - & $86.67 \mathrm{ab}$ & $20 \mathrm{~cd}$ & $6.67 \mathrm{ab}$ \\
\hline $10^{-7} \mathrm{E}+3 \mathrm{TDZ}$ & $93.33 a b$ & $47.67 \mathrm{abcd}$ & - & $22.33 \mathrm{~cd}$ & $6.67 \mathrm{~cd}$ & $8.33 a b$ \\
\hline $10^{-5} \mathrm{~T}+1 \mathrm{TDZ}$ & 100 a & $29 \mathrm{bcd}$ & $13.33 b$ & 61 abcd & $52.67 \mathrm{abc}$ & $26.67 \mathrm{ab}$ \\
\hline $10^{-5} \mathrm{~T}+2 \mathrm{TDZ}$ & $100 \mathrm{a}$ & $51.33 \mathrm{abcd}$ & - & - & - & - \\
\hline $10^{-5} T+3 \mathrm{TDZ}$ & $100 \mathrm{a}$ & 16 bcd & $33 \mathrm{~b}$ & 45 abcd & $37 \mathrm{bcd}$ & $42.33 \mathrm{ab}$ \\
\hline $10^{-6} \mathrm{~T}+1 \mathrm{TDZ}$ & $100 \mathrm{a}$ & 18 bcd & $4.33 \mathrm{~b}$ & $11 \mathrm{~cd}$ & - & $6.67 \mathrm{ab}$ \\
\hline $10^{-6} \mathrm{~T}+2 \mathrm{TDZ}$ & $79 a b$ & $7.33 \mathrm{~d}$ & $7.33 b$ & $22.33 \mathrm{~cd}$ & $5.67 \mathrm{~cd}$ & - \\
\hline $10^{-6} \mathrm{~T}+3 \mathrm{TDZ}$ & $75 a b$ & $21.67 \mathrm{bcd}$ & $4.33 \mathrm{~b}$ & $8.33 \mathrm{~cd}$ & - & $4.67 \mathrm{ab}$ \\
\hline $10^{-7} \mathrm{~T}+1 \mathrm{TDZ}$ & $53.33 b$ & $33.33 \mathrm{bcd}$ & - & - & - & - \\
\hline $10^{-7} \mathrm{~T}+2 \mathrm{TDZ}$ & $60 \mathrm{ab}$ & $53.33 \mathrm{abcd}$ & $5.67 \mathrm{~b}$ & $15.33 \mathrm{~cd}$ & - & - \\
\hline $10^{-7} \mathrm{~T}+3 \mathrm{TDZ}$ & $65.33 \mathrm{ab}$ & $25 \mathrm{bcd}$ & - & $16.67 \mathrm{~cd}$ & $16.67 \mathrm{~cd}$ & $16.67 \mathrm{ab}$ \\
\hline LSD0.01 & $44.86^{*}$ & $49.61 *$ & $33.22 *$ & $50.75^{*}$ & $42.46^{*}$ & $48.8^{*}$ \\
\hline
\end{tabular}

* Değerler açı transformasyonu yapılmış değerlere aittir.

Diğer hormon kombinasyonları da belirgin bir şekilde embriyogenik kallus ve sürgün oluşumunu etkilemiştir. Çeşitler arasında ise embriyogenik kallus ve sürgün oluşumunun istatistiki açıdan önemli olduğu tespit edilmiştir
(Çizelge 4). En yüksek kallus ve sürgün oluşumu Gordiyon çeşidinde gözlenirken kök oluşumunda çeşitler arasında önemli bir farklılık gözlenmemiştir. Öte yandan farklı çalışmalarda memeli cinsiyet hormonlarının kallus oluşumu, 
bitki fizyolojisinde çimlenme, embriyo gelişimi, ayrıca büyüme, gelişme ve çiçeklenme üzerine farklı konsantrasyonlarda uyarıcı rol oynadığı belirlenmiştir (Janeczko, 2000). Nitekim çalışmamızda genel olarak kallus ve kök oluşumunda estrone ve testesteronun kombinasyonlarının etkili olduğu gözlenmiştir. Bulgularımızla uyumlu olan bir araştırmada Androstenedion Arabidopsis thaliana L.'nın kallus dokusu verimini uyardığı gözlemlenmiştir (Janeczko, 2000;2003). Öte yandan Androsteron $(1 \mu \mathrm{M})$ çimlenmeyi ve scutellumda kallus dokusunun oluşumu yanında kışlık buğdayın olgun olmayan embriyolarının gelişimini artırdığıda rapor edilmiştir (Janeczko, 2000;2003). Genel olarak östrojenlerin olgun olmayan embriyoların çimlenmesini sınırladığı fakat kallus dokusunun oluşumunu önleyemediği bilinmektedir. Domates ve fasulyede görülen epinasti ve yaprak kıvrılması gibi morfolojik anormallikler östrojenlerle tedavi edilebilmiştir (Guan, 1988ab). 20. yy’ın başlarında yapılan çalışmalarda östrojenin in-vitro şartlarda bezelye embriyo izolatının gelişimini uyardığı belirlenmiştir (Bonner ve Axtman, 1937). Bitkide $0.1 \mu \mathrm{g}$ konsantrasyonunda olan östron Pisum sativum L. fidelerinin yaklaşık \%40'ında büyümeyi teşvik ettiği belirlenmiştir (Kopcewicz, 1969). Bhattacharya ve Gupta (1981), ayçiçeği fidelerine farklı konsantrasyonlarda her bir bitkiye uyguladıkları $0.25 \mu \mathrm{g}$ progesteron ve $17 \beta$ östradiol'un sürgün gelişimini artırdığını fakat kök gelişimini engellediğini, $0.1 \mu \mathrm{g}$ uygulamasının ise kök uzamasını artırdığını, her bir bitki için 0.1 ve $0.25 \mu \mathrm{g}$ konsantrasyonlarındaki testosteron uygulamasının yan tomurcuk oluşumunu artırdığı saptanmıştır. Guan ve Roddick (1988b), domates fidelerine östrojen ve $17 \beta$-östradiol uygulayarak sürgün kesiminde sürgün sayısı yanında kök gelişiminin de azaldığını belirlenmişlerdir. Öte yandan bitkilerdeki fizyolojik süreçler sırasında memeli cinsiyet hormonlarının konsantrasyonlarında değişimlerin olduğu ve ayrıca bitkilere bu hormonların dışarıdan uygulanması sonrasında da hücresel aktivitelerde farklılıkların meydana geldiği birçok araştırmacı tarafından gözlemlenmiştir. Bajguz ve Czerpak (1996;2000) iki bölümde gerçekleştirdiği çalışmada $17 \beta$-östradiol tedavisinin (10-2M,10-7M) Chlorella vulgaris'de klorofil ve karateneoid içeriğini artırdığını bulmuşlardır. Hormonun 10-13M,10-16M konsantrasyonlarında Chlorella vulgaris'in gelişimini uyardığını ve olgun hücrelerde şeker ve protein içeriğini artırdığını belirtmişlerdir. Ayrıca araştırıcılar 10-8M,10-6M konsantrasyonlarındaki steroidlerin (östron, testosteron ve pregnenolon asetat) mısır bitkisinin büyümesini artırarak daha iyi ürün ve erken anter uyarımında tedavi edici olduklarını ortaya koymuşlardır. Bitkilerin generatif gelişimine steroidlerin tesirinin ilk belirtisi 1937' de Chouard tarafından yapılan çalışmada ortaya çıkmıştır. $\mathrm{Bu}$ çalışmada 17ß-östradiol'ün Callistephus sinensis L. bitkisinde generatif gelişimi uyardığı bulunmuştur. Daha sonra $17 \beta$-östradiol' ün Lemna minor L. bitkisinin çiçeklenmesini uyardığı belirlenmiştir (Cyzgan, 1962). Hıyarda 17 $\beta$ estradiol testosteron kadar dişi çiçek sayısını artırmıştır. Ayrıca bu hormonlar uygulanan hıyar bitkilerinde 1 . nod da ilk çiçeklenmeyi meydana getirirken kontrol bitkilerinde 4. nod da meydana geldiği görülmüştür (Gawienowski ve ark., 1971). Kopcewicz (1971) Ecballium elaterium L. bitkisinde östrojen uygulamasının dişi/erkek çiçek oranını artırdığını tespit etmiştir.

\section{Sonuç ve Öneriler}

Bu çalışmada Hasankale ve Gordiyon hıyar çeşitlerinin kotiledon yaprakları kullanılarak kallus geliştirme ve rejenerasyon ortamında 2,4D, estron ve testesteronun farklı kombinasyonları uygulanarak in-vitro şartları altında hormonların kallus oluşumunu artırdığı, büyüme üzerine olumlu etkiler gösterip kök ve sürgün oluşumunu ve embriyogenik kallus gelişimini hızlandırdığı gözlenmiştir. Ancak şimdiye kadar yapılan çalışmalardan elde edilen bilgiler, bu hormonları bitki hormonları olarak adlandırmamıza yetecek kadar fazla değildir. Bu sebeple bu tip hormonlara tarımda yeteri kadar önem verilmemekte ve kullanımı sadece laboratuarlarda sınırlı kalmaktadır. Oysaki bu hormonların etkileri detaylı bir şekilde araştırılarak bitki türleri için optimal koşullarının belirlenmesi sayesinde tarımsal ürünlerde çok rahat kullanılarak önemli faydalar sağlanabilir. Bu bağlamda sonraki çalışmalarda memeli cinsiyet hormonlarının özellikle tarımsal ve ekonomik öneme sahip bitki türlerinin çimlenme, büyüme-gelişme ve çiçeklenme gibi farklı yaşam safhalarında değişik konsantrasyonlarının uygulanıp, onların etkileri belirlenmeli ve çalışılan her bir bitki türü için optimum etkili hormon konsantrasyonları araştırılmalıdır.

Çıkar Çatışması Beyanı: Makale yazarları aralarında herhangi bir çıkar çatışması olmadığını beyan ederler.

Araştırmacıların Katkı Oranı Beyan Özeti: Yazarlar makaleye eşit oranda katkı sağlamış olduklarını beyan ederler.

\section{Kaynaklar}


Aydoğdu, M., Boyraz N. 2005. Bitki büyüme düzenleyicileri (Hormon) ve hastalıklara dayanıklılık. Bitkisel Araştırma Dergisi, 1: 3540.

Babaoğlu, M., Yorgancılar, M., Akbudak, M.A. 2001. Bölüm 1. Doku kültürü: Temel Laboratuvar Teknikleri. Bitki biyoteknolojisi I. Doku Kültürü ve Uygulamaları, Babaoğlu, M., Gürel, E., Özcan, S. S. Ü. Vakfı yayınları, Konya, Türkiye, 1-35.

Bajguz, A., Czerpak, R. 1996. Metabolic activity of estradiol in Chlorella vulgaris Beijerinck (Chlorophytaceae) Part 1. Content of photosynthetic pigments. Pol Arch Hydrobiol, 43: 421-426.

Bajguz, A., Czerpak, R. 2000. Metabolic activity of estradiol in Chlorella vulgaris Beijerinck (Chlorophytaceae) Part 2. Content of the cellular sugar and protein accumulation. Pol Arch Hydrobiol, 43: 427-430.

Barrington, E.J.W. 1979. in: Hormones and Evolution (E.J.W. Barrington, ed.) (pp. VIIXXI). London, Academic Press.

Bhattacharya, B., Gupta, K. 1981. Steroid hormone effects on growth and apical dominance of sunflower. Phytochemistry, 20: 989-991.

Bonner, J., Axtman, G. 1937. The growth of plant embryos in vitro. Preliminary experiments on the role of accessory substances. Proc Natl Acad Sci USA, 23: 453-457.

Chouard, P. 1937. Action combinee de la falliculine et la duree declairement sur la floraison des Reines-Marguerites. C.R.Acad. Sci.Paris,B, 126, 509.

Cyzgan, J.C. 1962. Blütenbildung bei Lemna minor nach Zusatz von Oestrogen. Naturwissenschaften 49:285-286

Erdal, S., Dumlupinar, R. 2010. Progesterone and $\beta$-estradiol stimulate seed germination in chickpea by causing important changes in biochemical parameters. Zeitschrift für Naturforschung C, 65(3-4):239-244.

Gawienowski, M., Cheney, R.W., Marsh, H.V. 1971. Alteration ofsex expression in the cucumber by testosterone and estradiol. Phytochemistry 10: 2033-2034.

Geuns, J.M.C. 1978. Steroid hormones and plant growth and development. Phytochem., 17: 1-14.

Güleryüz, M., 1982. Bahçe Ziraatinde Büyütücü ve Engelleyici Maddelerin Kullanılması ve Önemi (Heinz Jansen'den tercüme). Atatürk Üniv. Yay. No.599 Erzurum 130s.

Guan, M., Roddick, J.G. 1988a. Comparision of the effects of epibrassinolide and steroidal estrogens on adventitious root growth and early shoot development in mung bean cuttings. Physiol Plant, 73:426-431.

Guan, M., Roddick, J.G. 1988b. Epibrassinolide inhibition of development of excised, adventitious and intact root of tomato (Lycopersicon esculentum): comparison with the effects of steroidal estrogens. Physiol Plant, 74:720-726.

Helmkamp, G., Bonner, J. 1952. Some relationships of sterols to plant growth. Plant Physiol, 28: 428-436.

İslam, T. 2014. Department of Biotechnology, Bangabandhu Sheikh Mujibur Rahman Agricultural University, Gazipur-1706, Bangladesh

Janeczko, A. 2000. Influence of selected steroids on plant physiological processes - especially flowering induction (in Polish). PhD Dissertation, Agricultural University, Krakow, Poland

Janeczko, Z., Szybka, P. 2001. Induction and proliferation of callus of Polygonatum verticillatum L (in Polish). Conference materials of the 18th Meeting of the Polish Pharmaceutical Society "Pharmacy in the 21st century". Poznan, Poland, p 536.

Janeczko, A., Filek, W., Janeczko, Z. 2003. Proliferation of Arabidopsis thaliana callus on medium containing 4-androstene-3,17dione, 2,4-dichlorophenoxyacetic acid and benzylaminopurine (in Polish). Materials of conference "Biotechnology in biology, pharmacy and agriculture" 15-17 September 2003, Bydgoszcz, Poland, p 121.

Janeczko, A., Skoczowski, A. 2005. Mammalian sex hormones in plants. Folıa histochemica et cytobıologıca 43:71-79.

Janeczko, A. 2012. Steroids, 77:169-173.

Kılıç, Y. 2007. Fitohormonların Saplı MeG̣e (Quercus robur L.) 1+0 Yaşlı Fidan Morfolojik Karakterler Üzerine Etkisi.Y. Lisans Tezi, Gazi Üniversitesi Fen Bilimleri Enstitüsü, Ankara

Kopcewicz, J. 1969. Influence of estrone on growth and endogenous giberellins content in dwarf pea. Bull Sci C1.II, Vol. XVII, No 11-12.

Kopcewicz, J. 1971. Influence of steroidal hormones on flower sex expression in Ecballium elaterium (L.). Z Pflanzenphysiol, 65:92-94.

Kumlay, A.M., Eryiğit, T. 2011. Bitkilerde büyüme ve geliG̣meyi düzenleyici maddeler: Bitki hormonları. Iğdır Üni. Fen Bilimleri Enst. Der. 1(2):47-56.

Löve, A., Löve, D. 1945. Experiments on the effects of animal sex hormones on dioecious plants. Ark Botanik, 32A, No 15:1-60 
Milanesi, L., Boland, R. 2004. Presence of estrogen receptor (ER)-like proteins and endogenous ligands for ER in solanaceae. Plant Science, 166:397-404.

Sandor, T., Mehdi, A.Z. 1979. Hormones and Evolution (E.J.W. Barrington, ed.) pp. I-72, Academic Press, London

Sarin, R.,2005. Useful metabolites from plant tissue cultures. Biotechnology, 4(2):79-93.

Speranza, A. 2010. Into the world of steroids: A biochemical "keep in touch" in plants and animals.Plant Signaling and Behavior, 5(8):940-943 